\title{
Comparative Study on Dynamics around a Single Rising Bubble through Different Computational Software
}

\author{
Ashraf Azmi, Periyasamy Balasubramanian, Bawadi Abdullah, Nurul Hasan, and Ehsan Zhalehrajabi
}

\begin{abstract}
In this work, two models were developed for the dynamics prediction of a rising bubble in the Hallimond Tube using computational software. This study is emphasized on the pressure coefficient prediction between different computational software namely Star-CCM+ and Fluent. Results obtained from simulated data were compared to each other and were validated using the validation data. Spherical rigid solid with the radius of $0.00575 \mathrm{~m}$ was fixed for both of the software and the geometry developed in the computational model was designed solely based on the inner of Hallimond Tube flotation device. The Reynolds number is fixed at $\mathrm{Re}=100$, based on the free stream velocity and sphere diameter. Simulated results obtained from Star-CCM+ and FLUENT were in good agreement with the validation data. Highest percentage of difference between Star-CCM+ and FLUENT is observed at the vicinity of $63.1^{\circ}$ which is $3.57 \%$.
\end{abstract}

Index Terms - CFD, flotation, rising bubble, surface mesh.

\section{INTRODUCTION}

Bubble rising phenomena is related to separation and mixing of minerals, chemical and biochemical. The dynamics of a rising bubble plays a significant role in gas-liquid system which contributes to the efficiency of particle capturing in separation devices [1]-[3]. Therefore understanding the dynamics of a rising bubble is the fundamental of particle separation process.

Bubble rising dynamics and characterization were studied experimentally [4], [5]. However insufficient knowledge of fluid dynamics has rendered researchers into discovering the crucial of the dynamics of the flow past a sphere through computational fluid dynamics (CFD) software [1], [4], [6]-[8].

CFD shows great predictive capabilities to determine the dynamic behaviour around bubble surface [9], [10]. Apart from that CFD can provide data which is not obtainable from traditional experimental methods. Because of the dramatic increase in computing power over the last few decades, the usage of CFD for designing and optimizing unit operations has increased immensely. The outcome of this research will serve as a proof to determine the suitability of CFD packages on the dynamics of rising bubble through the pure water

Manuscript received September 13, 2013; revised November 5, 2013. This work was supported by the Department of Chemical Engineering, Universiti Teknologi PETRONAS under Graduate Assistantship Scheme 2012/13.

Ashraf Azmi, Periyasamy Balasubramanian, Bawadi Abdullah, and Ehsan Zhalehrajabi are with the Department of Chemical Engineering, Universiti Teknologi PETRONAS (e-mail: ashrafazmi88@gmail.com; tel.: +605-3688023).

Nurul Hasan is with Department of Chemical Engineering, Universiti Teknologi PETRONAS. study.

The CFD results largely depend on the computational domain and modeling [11]. In this study, Hallimond Tube (HT) is used as the flotation device since it is a well accepted method for testing of flotability [12]. A static spherical solid is used instead of rising bubble, therefore velocity of $0.25 \mathrm{~m} / \mathrm{s}$ is used as water flow velocity in order to match the phenomena of bubble rising in Hallimond Tube. Location of spherical solid was kept fixed at $(0,0)$ and the radius of spherical solid used is $0.00575 \mathrm{~m}$ and is kept constant for all test cases.

It is reported in the literature that bigger bubbles experience shape alteration [2], [3] and zigzag motion [1], [4], [3] and resulting in complications to the study. Therefore, a small rigid sphere is considered to counter with these problems.

Since, the primary aim of this study is dynamics around a single rising bubble, therefore this study is not an attempt to consider multiphase interactions of bubble and particle in the gas-liquid system. The main objective here is to determine the accuracy of the simulated data and therefore, Star-CCM+ V6.04 ${ }^{\circledR}$ and Fluent V13.0 ${ }^{\circledR}$ CFD software were used for comparison between the simulated data obtained.

\section{Model DescriPtions AND Test CASES}

For the computation, the general-purpose thermal fluid analysis Star-CCM+ ${ }^{\circledR}$ V6.04 and FLUENT ${ }^{\circledR}$ V13.0 constituting Laminar model was used. Fig. 1 shows the computational grid on the location of sphere and the layout of the analysis domain in axisymmetric 2-Dimensional. Quadral mesh was used for the surface meshing and validated by numerical simulation data [13]. By applying this surface mesh, a fluid flow past a rigid sphere had been simulated and grid-independent results were obtained. In this section, problem description, boundary conditions, computational grid and test cases are described.

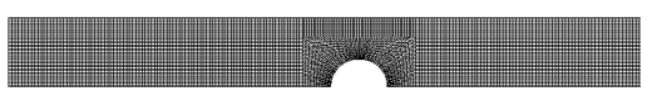

b

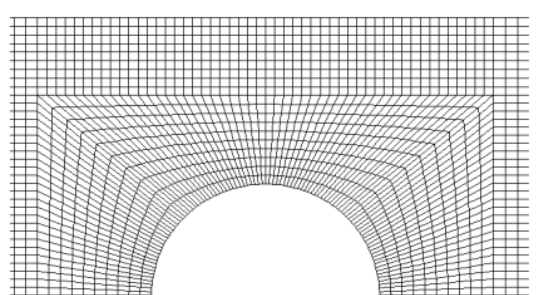

Fig. 1. The axysimmetric view on grid generation for the a) whole computational domain and b) close up on mesh around sphere. 
The continuity equation for 2D axisymmetric geometries [9] can be represented as

$$
\frac{\partial \rho}{\partial t}+\frac{\partial}{\partial x}\left(\rho v_{x}\right)+\frac{\partial}{\partial x}\left(\rho v_{r}\right)+\frac{\rho v_{r}}{r}=S_{m}
$$

The axial and radial momentum conservation equations are given by

$$
\begin{aligned}
& \frac{\partial}{\partial t}\left(\rho v_{x}\right)+\frac{1}{r} \frac{\partial}{\partial x}\left(r \rho v_{x} v_{x}\right)+\frac{1}{r} \frac{\partial}{\partial x}\left(r \rho v_{r} v_{x}\right) \\
& =-\frac{\partial p}{\partial x}+\frac{1}{r} \frac{\partial}{\partial x}\left[r \mu\left(2 \frac{\partial v_{x}}{\partial x}-\frac{2}{3}(\nabla \cdot \vec{v})\right)\right] \\
& +\frac{1}{r} \frac{\partial}{\partial r}\left[r \mu\left(\frac{\partial v_{x}}{\partial r}+\frac{\partial v_{r}}{\partial x}\right)\right]+F_{x}
\end{aligned}
$$

and

$$
\begin{aligned}
& \frac{\partial}{\partial t}\left(\rho v_{r}\right)+\frac{1}{r} \frac{\partial}{\partial x}\left(r \rho v_{x} v_{r}\right)+\frac{1}{r} \frac{\partial}{\partial r}\left(r \rho v_{r} v_{r}\right) \\
& =-\frac{\partial p}{\partial r}+\frac{1}{r} \frac{\partial}{\partial x}\left[r \mu\left(\frac{\partial v_{r}}{\partial x}+\frac{\partial v_{x}}{\partial r}\right)\right] \\
& +\frac{1}{r} \frac{\partial}{\partial r}\left[r \mu\left(2 \frac{\partial v_{r}}{\partial r}-\frac{2}{3}(\nabla \cdot \vec{v})\right)\right] \\
& -2 \mu \frac{v_{r}}{r^{2}}+\frac{2}{3} \frac{\mu}{r}(\nabla \cdot \vec{v})+\rho \frac{v_{z}^{2}}{r}+F_{r}
\end{aligned}
$$

where

$$
\nabla \cdot \vec{v}=\frac{\partial v_{x}}{\partial x}+\frac{\partial v_{r}}{\partial r}+\frac{v_{r}}{r}
$$

The problem stated in this work involves fluid flow past a sphere whose diameter (D) is $0.0115 \mathrm{~m}$. The Reynolds number is fixed at $\mathrm{Re}=100$, based on the fluid velocity and sphere diameter. In this study, the fluid velocity of $0.001 \mathrm{~m} / \mathrm{s}$ was considered to match the Reynolds ( $R e)$ number of literature paper [13] and a rigid spherical solid was

\begin{tabular}{|c|c|c|}
\hline Software & \multicolumn{2}{|c|}{ Star CCM+ ${ }^{\circledR}$ V6.04 and FLUENT ${ }^{\circledR}$ V13.0 } \\
\hline Model & \multicolumn{2}{|l|}{ Laminar } \\
\hline Grid System & \multicolumn{2}{|l|}{ Quadral mesh } \\
\hline Nodes & \multicolumn{2}{|l|}{9,620} \\
\hline Cells & \multicolumn{2}{|l|}{9,270} \\
\hline Faces & \multicolumn{2}{|l|}{18,889} \\
\hline \multirow{4}{*}{$\begin{array}{l}\text { Calculation } \\
\text { condition }\end{array}$} & \multicolumn{2}{|l|}{ Steady State } \\
\hline & Time step & $0.001[\mathrm{~s}]$ \\
\hline & Iteration time & $1000 \max$ \\
\hline & $\begin{array}{l}\text { Convergence } \\
\text { criteria }\end{array}$ & $10^{-6}$ \\
\hline \multirow{3}{*}{$\begin{array}{l}\text { Input } \\
\text { Condition }\end{array}$} & \multirow[t]{2}{*}{ Inflow } & Velocity inlet: $0.001[\mathrm{~m} / \mathrm{s}]$ \\
\hline & & Magnitude direction: $[-1,0,0]$ \\
\hline & Outflow & Pressure outlet: $0[\mathrm{~Pa}]$ \\
\hline \multirow[t]{2}{*}{$\begin{array}{l}\text { Analytical } \\
\text { area }\end{array}$} & \multicolumn{2}{|r|}{$0.1725(15 D)^{L} \times 0.014375(2.5 D){ }^{H} \mathrm{~m}$} \\
\hline & $\begin{array}{l}\text { Sphere } \\
\text { position }\end{array}$ & $(0,0)$ \\
\hline
\end{tabular}
considered as bubble and was located at $(0,0)$. The solution domain is bounded by the inlet, the outlet, the sphere wall, and the cylinder wall as shown in Fig. 2.

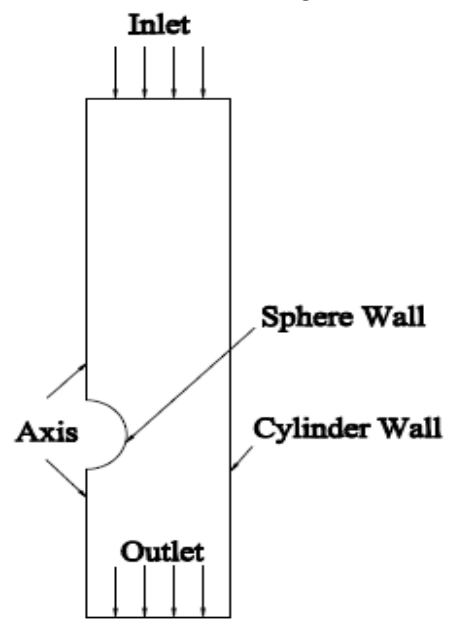

Fig. 2. Analysis domain imposed with boundary conditions.

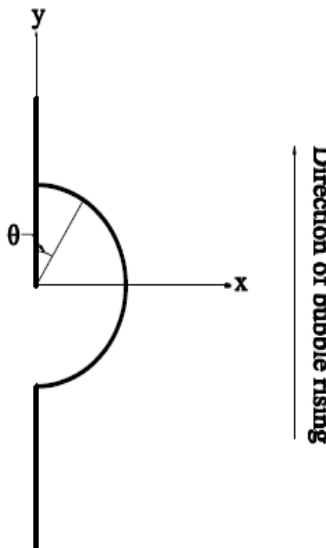

Fig. 3. Direction of bubble rising in 2D-axysimmetric domain.

TABLE I: BOUNDARY CONDITIONS

The boundary conditions for the analysis are shown in Table I. The direction magnitude of bubble rising simulation is shown in Fig. 3.

The grids were generated in GAMBIT and were solved in the Star-CCM+® V6.04 and FLUENT ${ }^{\circledR}$ V13.0. The coarse grid consists of 9,620 nodes, 9,270 cells and 18,889 faces were used. It is important that the grids of the domain need to be properly refined in order to predict the dynamics around the study object accurately, especially around the study object.

The standard SIMPLE algorithm and the first order implicit formulation were used. The computational effort required to achieve the desired level of accuracy were significantly reduced using the solution-adaptive refinement technique implement in both of the software. Convergence 
was obtained when the maximum scaled residuals were less than $10^{-10}$ for both of the software.

\section{RESULTS AND DISCUSSION}

Fig. 4 shows the pressure coefficient, $C_{P}$ distributions by interactions of the bubble with the fluid flow in a Hallimond Tube (HT). In Fig. 4, $\theta$ shows the angle measured from periphery of the sphere wall. Three cases were shown in Fig. 4 including validation paper data [13], and computational data from Star-CCM+ and FLUENT commercial software. The pressure coefficient for fluid around a rigid sphere decreases with an increase in $\theta$ from $0^{\circ}$ to $70^{\circ}$. Simulated results obtained using Star-CCM+ and FLUENT were in good agreement with the numerical simulation of Magnaudet et al. [13].

Fig. 5 shows the axial velocity $v_{z}$, distributions by the surface of the sphere wall from. The trend of the data from Star-CCM+ and FLUENT in Figs. 4 and 5 clearly explain the relation between dimensionless $C_{P}$ and $v_{z}$ values. Here, $C_{P}$ is inversely proportional to $v_{z}$. It is assumed that fluid velocity around sphere wall in FLUENT is higher as compared to fluid velocity around sphere wall in Star-CCM+ as shown in Fig. 5 and this findings explained the trend of the computational data in Fig. 4. The highest percentage of difference between Star-CCM+ and FLUENT is observed at the vicinity of $63.1^{\circ}$ which is $3.57 \%$ (see Fig. 5).

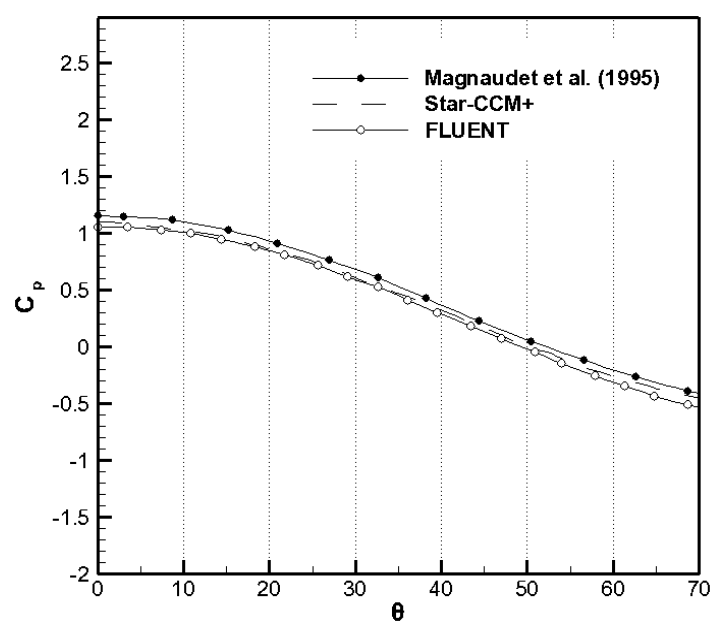

Fig. 4. Pressure coefficient comparison for flow around a rigid sphere.

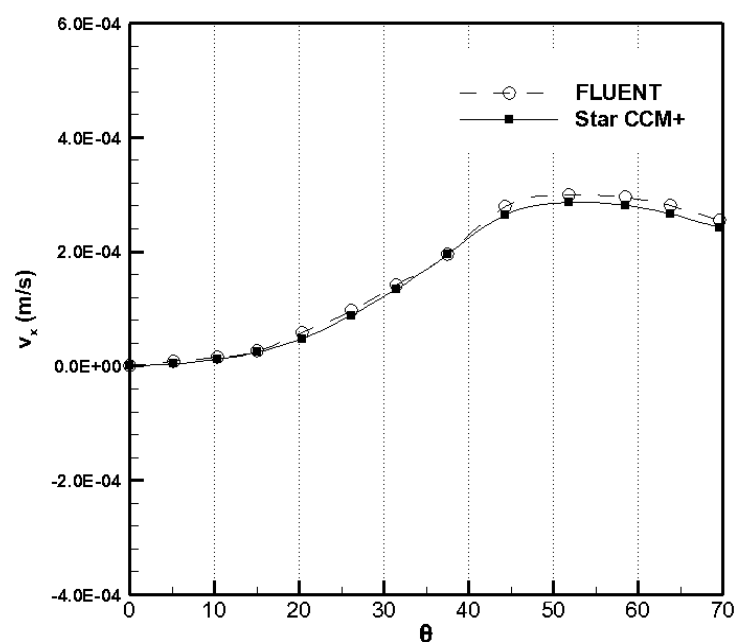

Fig. 5. Axial velocity comparison for flow around a rigid sphere.

\section{CONCLUSION}

In this paper, the relationship between the pressure coefficient and the axial velocity distribution on a rising bubble was investigated by Star-CCM+ and FLUENT software. It was observed that the simulated results obtained using Star-CCM+ shows good agreement with FLUENT simulated results.

\section{NOMENCLATURE}

$\begin{array}{lll}R e & \text { Reynolds Number } & - \\ \rho & \text { Fluid Density } & \mathrm{kg} / \mathrm{m}^{3} \\ v_{x} \quad \text { Axial velocity } x \text {-direction } & \mathrm{m} / \mathrm{s} \\ v_{r} \quad \text { Axial velocity } r \text {-direction } & \mathrm{m} / \mathrm{s} \\ r \quad \text { Radial coordinate } & \mathrm{m} \\ S_{m} \text { Source term } & - \\ \vec{v} \quad \text { Velocity vector } & \mathrm{m} / \mathrm{s} \\ F_{x} \quad \text { Body force } x \text { - direction } & \mathrm{N} \\ F_{r} \quad \text { Body force } r \text { - direction } & \mathrm{N} \\ v_{z} \quad \text { Swirl velocity } & \mathrm{m} / \mathrm{s} \\ \mu & \text { Kinematic viscosity } & \mathrm{kg} / \mathrm{m}-\mathrm{s} \\ p & \text { Pressure } & \mathrm{Pa} \\ p_{r e f} & \text { Reference Pressure } & \mathrm{Pa} \\ \rho_{f} & \text { Fluid Density } & \mathrm{kg} / \mathrm{m}^{3} \\ v_{f} & \text { Velocity of the fluid } & \mathrm{m} / \mathrm{s}\end{array}$

\section{ACKNOWLEDGEMENT}

This work was supported by the Department of Chemical Engineering, Universiti Teknologi PETRONAS under Graduate Assistantship Scheme 2012/13.

\section{REFERENCES}

[1] N. M. S. Hasan, M. M. K. Khan, and M. G. Rasul, "A study of bubble trajectory and drag co-efficient in water and non-newtonian fluids," WSEAS Transactions on Fluids Mechanics, vol. 3, no. 3, pp. 262-270, 2008.

[2] G. Bozzano, and M. Dente, "Shape and terminal velocity of single bubble motion: A novel approach," Computers \& Chemical Engineering, vol. 25, no.4-6, pp. 571-576, 2001.

[3] D. Xu, I. Ametov, and S. R. Grano, "Detachment of coarse particles from oscillating bubbles - the effect of particle contact angle, shape and medium viscosity," International Journal of Mineral Processing, vol. 101, issue 1-4, pp. 50-57, 2011

[4] A. A. Kulkarni, and J. B. Joshi, "Bubble formation and bubble rise velocity in gas-liquid systems: A review," Industrial \& Engineering Chemistry Research, vol. 44, no. 16, pp. 5873-5931, 2005.

[5] L. Parkinson and J. Ralston, "Dynamic aspects of small bubble and hydrophilic solid encounters," Advances in Colloid and Interface Science, vol. 168, issue 1-2, pp. 198-209, 2011.

[6] A. A. Kulkarni, "Lift force on bubbles in a bubble column reactor: experimental analysis," Chemical Engineering Science, vol. 63, pp. 1710-1723, 2008.

[7] P. T. L. Koh, and M. P. Schwarz, "CFD modelling of bubble-particle attachments in flotation cells," Minerals Engineering, vol.19, issue 6-8, pp. 619-626, 2006.

[8] N. Hasan, "Comparison of a computational model of single bubble collection efficiency in a hallimond tube," in Proc. Seventh International Conference on CFD in the Minerals and Proces Industries CSIRO, Melbourne, Australia, 2009.

[9] Ansys Fluent User's Guide, (Release 13.0), Fluent, 2010.

[10] User Guide, Star-CCM+Version 6.04.014, Star-CCM+, 2011. 
[11] A. Azmi, P. Balasubramanian, B. Abdullah and E. Zhalehrajabi, "Sensitivity of the CFD mesh for a single rising Bubble in a hallimond tube." Applied Mechanics and Materials, vol. 372, pp. 26-29, 2013.

[12] D. W. Fuerstenau, Froth Flotation, New York: AIME, 50th Anni-versary Volume, 1962.

[13] J. Magnaudet, M. Rivero, and J. Fabre, "Accelerated flows past a rigid sphere or a spherical bubble. part 1. steady straining flow," Journal of Fluid Mechanics, vol. 284, pp. 97-135, 1995.

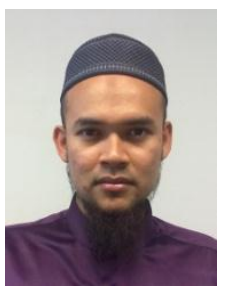

Ashraf Azmi is MSc Student of Chemical Engineering in Universiti Teknologi PETRONAS. He was born in Kuala Lumpur, Malaysia in 1986. He did his first degree in Univerisiti Malaysia Sabah majoring in Chemical Engineering Processing. Dr. Periyasamy Balasubramanian is a senior lecturer in Faculty of Chemical Engineering, Universiti Teknologi PETRONAS. Dr. Bawadi Abdullah is a senior lecturer in Faculty of Chemical Engineering,
Universiti Teknologi PETRONAS. Dr. Nurul Hasan is a former senior lecturer in Faculty of Chemical Engineering, Universiti Teknologi PETRONAS. He is specialized in fluid dynamics modeling and simulation. He is well known among the Computational Fluid Dynamics (CFD) experts for his vast experience and knowledge of CFD. Ehsan Zhalehrajabi is MSc Student of Chemical Engineering in Universiti Teknologi PETRONAS. 